\title{
Plastic hinge of reinforced concrete beam based on fiber element model
}

\author{
Chen Xiaoming ${ }^{1,}$, Duan Jin and Li Yungui \\ ${ }^{1}$ China state construction technical center, Beijing, China \\ aHanee@126.com
}

\begin{abstract}
Keywords: Plastic hinge, Fiber element, Reinforced concrete
Abstract. Plastic hinge can be used easily to optimize the reinforced concrete structures, but compared with fiber element model used widely in general FEA software, it cannot present accurate solutions for some complex problems. In order to propose visualized results of structural damage for fiber element method, numerical method is used to develop criterions for plastic hinge. Numerical results show that compared with yield point of tension steel and stiffness degradation of section, compression damage of concrete can be easily used as the best criteria, and the proper values is also proposed. With this method, engineers can master the macro damage of structures in fiber element method.
\end{abstract}

\section{Introduction}

In the process of design, maximum displacement angle is the most important criteria for avoiding structural collapse under rare earthquake. For those most important structures, key members can be designed keeping elastic at any cost, but it is uneconomic for most of structures, which should be designed with predictable and controllable damage. Usually plastic hinge is used as the most effective criteria for controlling damage of members in professional software designed for structural analysis. Engineers can make structural optimization easily according to those critical members shown with plastic hinge method.

With reasonable length assumption and curves of force-displacement, plastic hinge can be defined as moment hinge, shear force hinge or PMM hinge. The nonlinearity of hinge models would be controlled with the parameters defined by engineers. Based on the experiments for specific sections, the macro property of members can be simulated accurately with plastic hinge model. Otherwise, the micro damage of material isn't the concern of this method. But deficiency lies in that structural test cannot be used for each kind of complex sections, such as steel reinforced concrete or some irregular sections, where hypothesis for constitutive relationship of member and length of hinge isn't reliable any longer.

Fiber element method is more adaptable than plastic hinge. In fiber element model, section is meshed into virtual fibers, and the tangent mechanical property of each fiber can be simulated with uniaxial constitutive relationship easily. As the mechanical property of material can be formulated with experiments and it would not change with section forms significantly, thus if both section and member are meshed finely enough, results of each point in the member can be simulated accurately. For concrete members, compression damage is taken as the criteria in fiber element model. Compared with plastic hinge, this criterion is much more obscure for engineers.

These two kinds of model are integrated by some structural software [1], fiber element model is used for mechanical analysis, and plastic hinge is defined by stiffness degradation for damage criterion. Difference with these structural software, although those general finite element software as ABAQUS[2] are powerful for nonlinear concrete structures by using fiber element method, engineers cannot make it clear that whether the members have lost their load carrying capability after being damaged seriously.

A reinforced concrete framework under horizontal displacement loads is analyzed by using fiber element method to discover the affection of micro damage on section stiffness and load carrying capability. By this research, engineers can get macro damage as plastic hinge in general FEA software. 


\section{Fiber element model}

Section is meshed into many fibers as shown in Fig.1(a), and each fiber in section is simulated by according integral point(Fig 1.b) with uniaxial constitutive relationship.

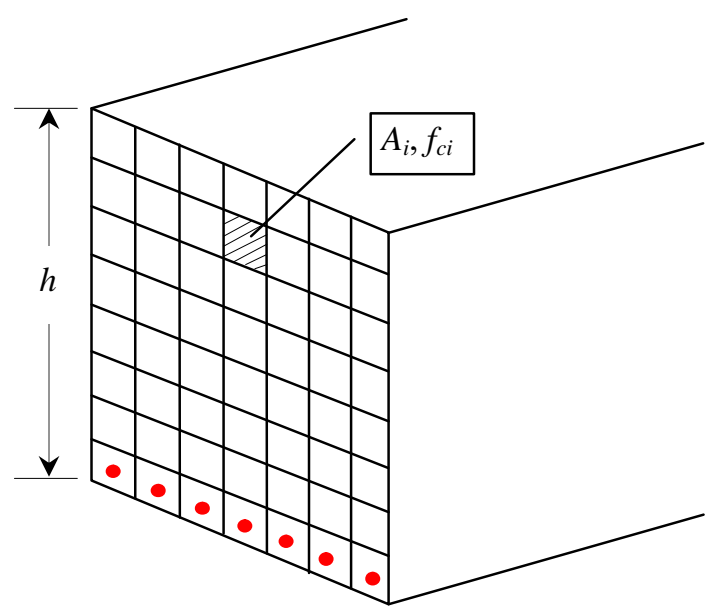

(a)Fibers of section

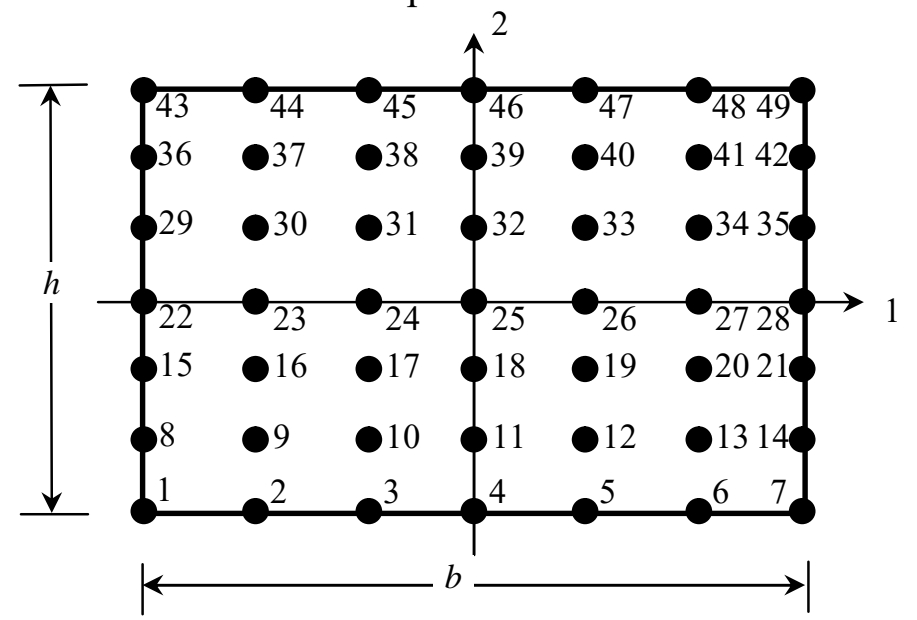

(b) Integration points of concrete section

Fig. 1 Fiber element model

User can select different meshes at the basis of accuracy. For a rectangular section, integral scheme of $7 \times 7$ is shown in Fig 1.b. If rebar is embedded into the section, additional integral points would be applied.

Along the tangent direction, each concrete fiber is simulated with constitutive relationship[3], then stress of a fiber can be formulated as follows:

where

$$
\begin{aligned}
& \sigma_{t}=\left(1-d_{t}\right) E_{0}\left(\varepsilon_{t}-\varepsilon_{t}^{p l}\right) \\
& \sigma_{c}=\left(1-d_{c}\right) E_{0}\left(\varepsilon_{c}-\varepsilon_{c}^{p l}\right)
\end{aligned}
$$

$\sigma_{t}, \sigma_{c}$ is the stress of tension and compression respectively;

$d_{t}, d_{c}$ is the damage of tension and compression respectively;

$E_{0}$ is the initial elastic modulus;

$\varepsilon_{t}, \varepsilon_{c}$ is the strain of tension and compression respectively;

$\varepsilon_{t}^{0}, \varepsilon_{c}^{p l}$ is the effective plastic strain of tension and compression respectively.

Skeleton and damage curves of $\mathrm{C} 40$ concrete are shown in Fig.2:

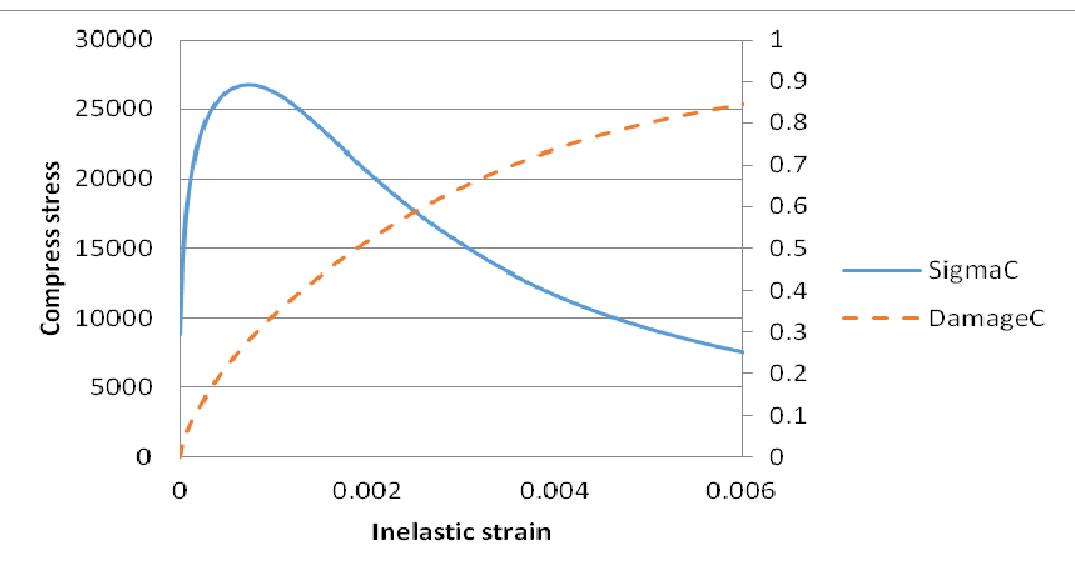

Fig. 2 Skeleton and damage curves of $\mathrm{C} 40$ concrete

The bending moment and axial force of the section can be formulated by integration of each fiber as follows: 


$$
\begin{aligned}
& M_{x}=\sum_{i=1}^{n} A_{i} h_{y} \sigma_{i} \\
& M_{y}=\sum_{i=1}^{n} A_{i} h_{x} \sigma_{i} \\
& N=\sum_{i=1}^{n} A_{i} \sigma_{i}
\end{aligned}
$$

\section{Plastic hinge model}

For a reinforced concrete beam, the tensional rebar should be designed to yield firstly as the load increasing, and then concrete in compression area would be damaged as the strain of tensional rebar increased, the load capacity may decrease after the peak value with drilling angle increase rapidly, this means that the section has degraded to a plastic hinge.

The experimental observation for concrete is that the compressive stiffness is recovered upon crack closure as the load changes from tension to compression. Thus although the beam end may bearing moment of different direction, the plastic hinge at the beam end could be simplified as a one-way hinge.

Compared with material constitutive relationship for fiber element method, plastic hinge is the constitutive relationship of force and displacement for members includes the research on length of hinge $[4,5,6]$, and the research on hysteretic curves $[7,8]$

\section{Numerical example}

Reinforced concrete framework shown in Fig.3 is analyzed. Horizontal displacement load is applied at the top of columns from zero to maximum amplitude $5 \mathrm{~cm}$ in one second. The mesh length is $0.5 \mathrm{~m}$ simulated by using Euler-Bernoulli beam element with three integral points. Combined with load bearing capacity of beam section, plastic hinge of beam end is researched by strain of rebar and damage of concrete.

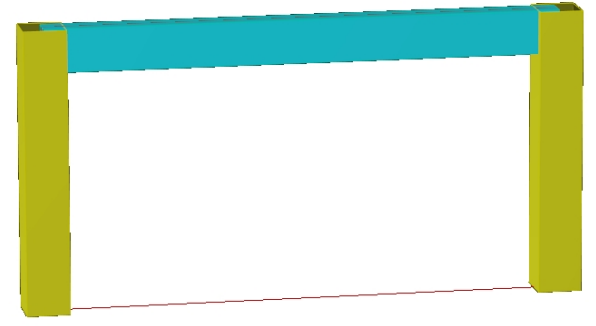

Fig.3 Reinforced concrete framework

\section{Numerical results}

Curves of moment at beam end and drilling angle at the left joint of beam are shown in Fig.4. It can be seen that the load bearing capacity of beam end decreased dramatically at $0.6 \mathrm{~s}$ when the horizontal displacement reached $3 \mathrm{~cm}$. it denoted that the beam end degraded into a plastic hinge. According to the principle of structural design, plastic hinge is the behavior of beam end but not the joint, so it needs to be emphasized that this drilling angle is not equal to the rotation of beam end, but it still can prove that the inflection point of drilling angle and the decrease of moment is nearly at the same time. 


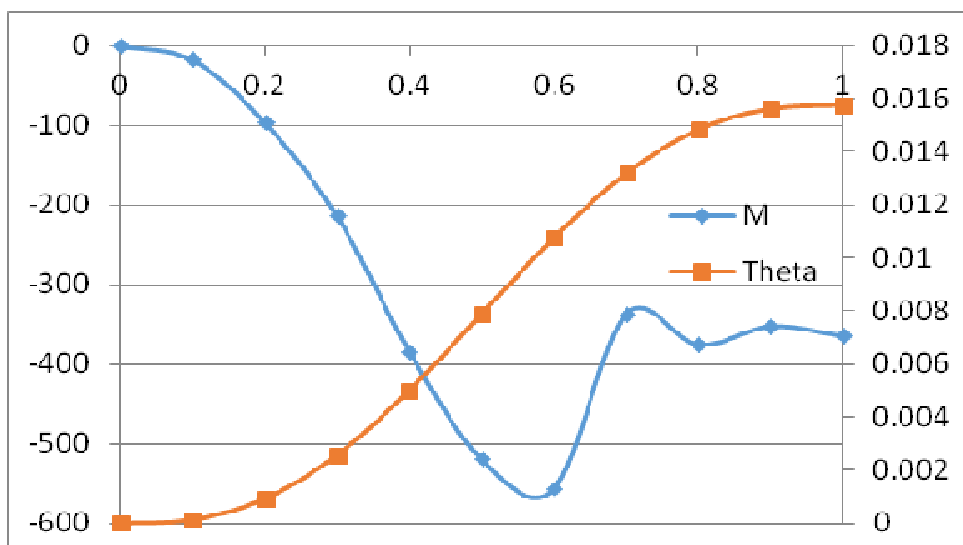

Fig.4 Curve of M Theta

The section moments at each integration points(1/2/3 is the point number from left to right) of element at the left end are shown in Fig.5. From Fig. 5(a), integration point 1 of leftmost, the load bearing capacity of concrete section decreased significantly after the peak value, the bending moment carried by steel section at integration point 1 and 2 increased at the same time which means that load has been transferred from concrete to rebar. From Fig. 5(b), the total moment carried by both concrete and steel at point 1 also decreased after the peak value, and the moment being transferred to point 3 decreased because of the stiffness degradation of point 1.

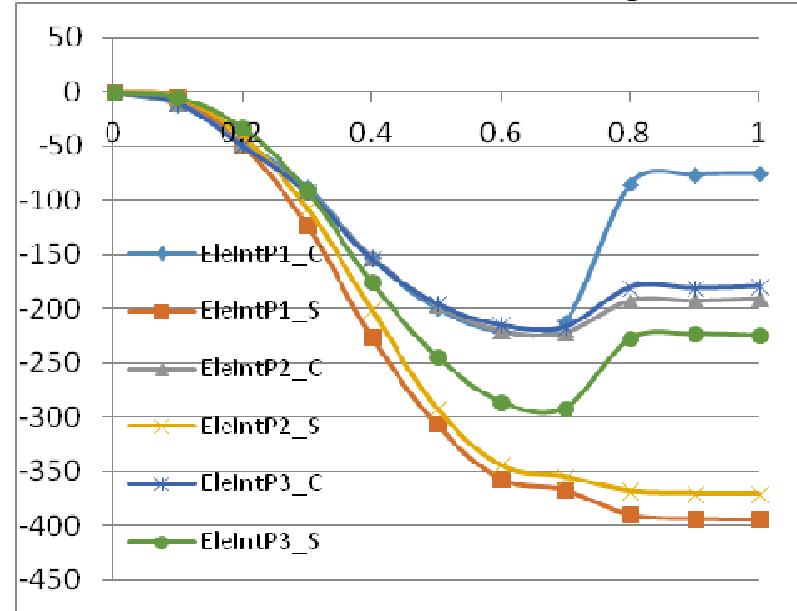

(a) Moment of concrete and steel

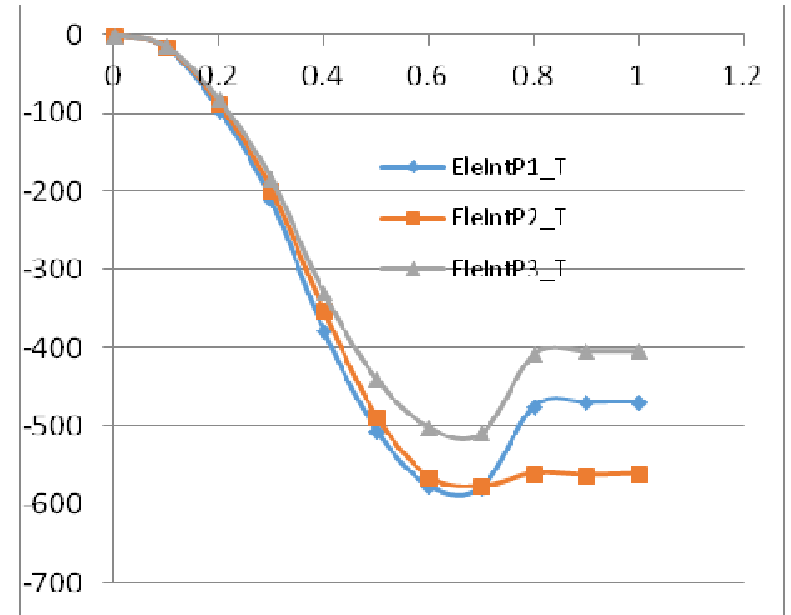

(b) Moment of whole section

Fig.5 Moment of the leftmost element at integration points

Compression damage of concrete fiber at element integration points are shown in Fig.6. Fiber 32, 39 and 46 are damaged seriously at the elemental integration point 1, only fiber 46 is damaged seriously at elemental integration point 2 , and no compression damage is greater than 0.3 at point 3 .

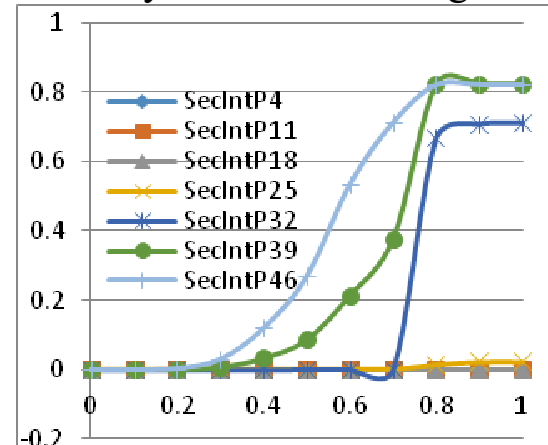

(a) Elemental integration point 1

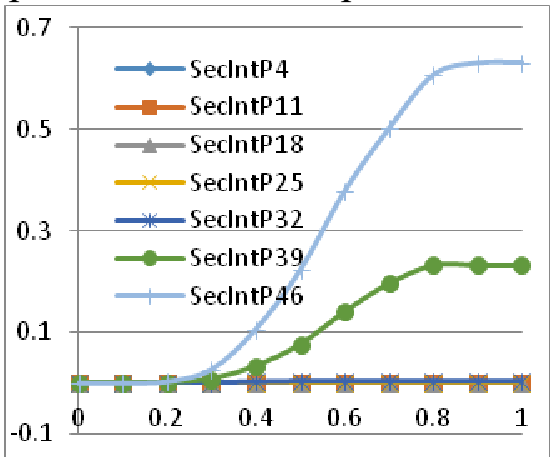

(b) Elemental integration point 2

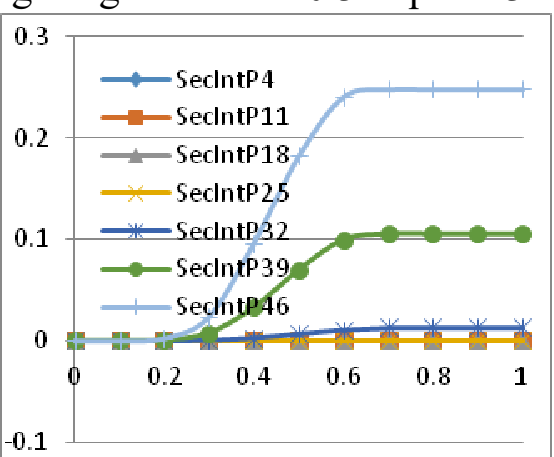

(c) Elemental integration point 3

Fig.6 Compression damage of concreter fibers

The steel strain curves at the beam bottom are shown in Fig.7. Plastic strain increased at elemental integration point 1 and 2 , but it is equal to zero at point 3 . 


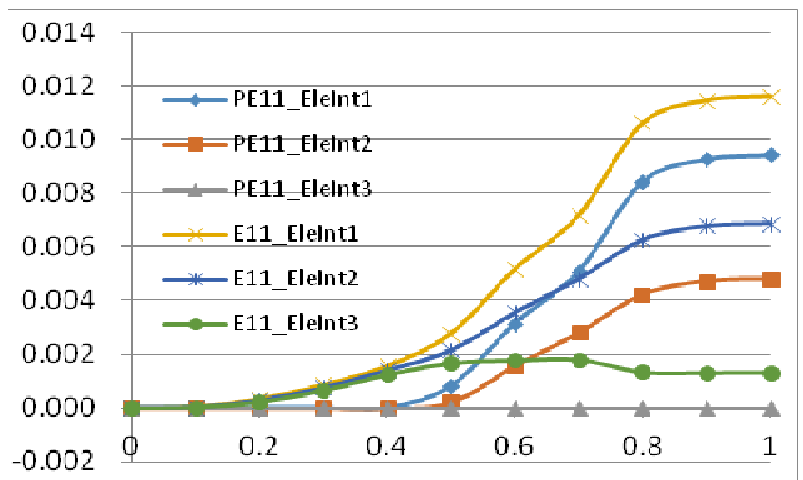

Fig.7 Total strain E11 and plastic train PE11 at the bottom

The steel plastic strain increased after $0.4 \mathrm{~s}$ as shown in Fig.7, the concrete is damaged seriously after $0.5 \mathrm{~s}$ as shown in Fig.6, and the load bearing capacity decreased after $0.6 \mathrm{~s}$ as shown in Fig.4 and Fig.5, thus these degradations are not synchronic. The definition of plastic hinge is that the drilling angle increased with the load bearing capacity decreased as the phenomenon occurred at $0.6 \mathrm{~s}$. In fact, beam is always designed as that the tension rebar should yield before the compression concrete being damaged seriously to avoid brittle failure, and the load bearing capacity will increased more or less after yield point because of the strengthening effect of steel. It can be seen that these three degradation all can taken as the criterion of plastic hinge, but in fiber element model, researchers prefer to take 0.3 as the critical value to evaluate whether concrete has been damaged seriously, which value is just can be located between the other two, so it is the best criterion.

\section{Conclusion}

Fiber element model is used widely in general FEA software for analysis of reinforced concrete. With constitutive relationships of concrete and steel, this method can be used in any complex forms, but visualized results as plastic hinge cannot be proposed by this method. By using numerical method, criterion for plastic hinge is researched in this paper, compared with yield point of tension steel and stiffness degradation of section, compression damage of concrete can be easily used as the best criterion, and the critical value can be taken as 0.3 which is also the criterion of judgment for concrete damaged seriously under compression.

\section{References}

[1] China architecture \& building press. Structural analysis and design software tutorial - ETABS Chinese version of the guide. Beijing, China,2004.

[2] ABAQUS Inc. ABAQUS UserManual, V6. 5. 5. 2006

[3] China architecture \& building press. Technical specification for concrete structures of tall building, Beijing, China, 2010.

[4] Li Guiqian. Equivalent plastic hinge length of circular reinforced concrete bridge columns. China Civil Engineering Journal. 2016, 49(2): 87-97

[5] Li Zhenbao. Size effect on plastic hinge length of reinforced concrete columns. Journal of Beijing University of technology. 2014, 40(9):1334-1340

[6] Yang Deshan. Research on plastic hinge length of steel tubular column filled with steel-reinforced concrete. Building Structure. 2017, 47(1):100-103.

[7] Lu XinZheng, Ye Lieping, Miao Zhiwei. Elasto-plastic Analysis of Buildings Against Earthquake. China Architecture \& building press. Beijing, 2015.

[8] Ding Xiaoyan, Pan Zhihong. Study on plastic hinge model of earthquake damaged RC frame structure. Earthquake Resistant Engineering and Retrofitting. 2016,38(6):48-54 